\title{
USAGE OF DYNAMIC SIMULATION IN PRESSING SHOP PRODUCTION SYSTEM DESIGN
}

\author{
Tvrdon, L. ${ }^{*} \&$ Fedorko, G.* \\ ${ }^{*}$ Vysoká škola logistiky o.p.s., Palackého 1381/25, 75002 Přerov, Czech Republic \\ ${ }^{* * *}$ Faculty of Mining, Ecology, Process Control and Geotechnology, Technical University of Košice, \\ Letná 9, 04200 Košice, Slovak Republic \\ E-Mail: leo.tvrdon@vslg.cz, gabriel.fedorko@tuke.sk
}

\begin{abstract}
Production systems present a different complex consisting of interconnected sub-units. For their proper functioning, it is necessary to use approaches in the design process that will fully accept the interaction of individual units. A dynamic simulation is now a powerful tool for the need of designing production systems. However, in its application in practice, we often encounter various. This paper presents a framework for using dynamic simulation in production systems design. It describes suggested steps to take when we start the process of production systems design, mainly the process of data collection and simulation model building (current and future virtual systems). The article details framework usage and describes the most important challenges of each step. The proposed framework is then successfully applied to a real-life project of innovation of a production system in a pressing shop, where every step of the framework is documented with a working example and with described difficulties or outcomes that each step gave to the team. The result of the dynamic simulation application at the presented real example by the software Witness, the saving was 40.000 EUR.

(Received in August 2019, accepted in March 2020. This paper was with the authors 4 months for 3 revisions.)
\end{abstract}

Key Words: Simulation, Modelling, Production Systems, Logistics

\section{INTRODUCTION}

Designing production systems is a long-term project and the quality of this design often determines the success or failure of a company [1]. But the pressure on quickening the process of designing production systems grows with the rapid development of society, where more and more attention is given to speed and efficiency. The project managers and engineers can use a lot of techniques to make this possible, mainly through an analytical solution of mathematical models [2,3]. For example, methods of operations research such as linear programming or graph theory can be used to tackle difficulties of production systems design. The works of many authors are focused on this issue $[4,5]$.

By design of production systems, it is necessary to take into account several factors, among which the way of supplying of workplaces has an important role. The way of supplying has an effect on the realization of the production process. Production processes and their logistics support are organizationally and operationally interconnected [6]. The organization of production systems can be organized in various ways. Hajduk et al. [7] described the application of flexible production cell within the production system for the realization of flexible production. Different mathematical methods are often used to design production systems.

However, mathematical methods are largely time-consuming, often tend to oversimplify the reality when constructing models to be able to successfully solve them, and their results can be misinterpreted easily by the managers due to very scientific approach. And there are also highly dynamic and probabilistic systems that are too complicated for us to be able to solve them analytically. That is why the scientists and practical designers alike are trying to find new methods that would be more elegant to present and would provide another means to design the production system [8-12]. 
The simulation presents for the design of production systems a method with high potential. It is a fast and adaptive method that is highly efficient and adaptable. Hsieh [13] applied hybrid analytical and simulation models for the design of assembly line and for the planning of production. In his work, he takes a closer look at hybrid approaches and their application, proposes a new class of hybrid modelling and illustrates the cost function for selection of analytical or simulation model approaches. Yang et al. [14] used the method of simulation for the realization of optimization by design of Lean production system. Another example of simulation applying by design of production and logistics system is presented by Dias et al. [15]. They describe the design of a production system for the need of internal logistics in the automotive industry. They use the integrated design of systems (IDS) which was designed and described in Vik et al. $[16,17]$. Discrete event simulation (DES) is most often used for designing of production systems. It can be mentioned in the publication [18] as an example of its application for the need for analysis of the production system.

Popovics et al. [18] applied DES for testing of validation of KPI indicators. The reliability of simulation models is an important factor by application of simulations. There are currently several approaches to its verification; one is presented by Sargent [19]. He deals in his publication with validation and verification of the simulation model and uses four different approaches and two different paradigms. Similarly, Xu and Yin [20], approached to the verification of a discrete production system, and they used the decision-making model. We can also use dynamic programming by design of production systems, as it is described by Sadeghpour et al. [21] or we can apply dynamic simulation.

Dynamic simulation is one of the relatively new methods but is becoming widely popular in companies and thus it is beneficial to both scientists and practitioners to describe appropriate framework on how to work with this simulation and how to prepare a model to be able to simulate on it.

Based on current knowledge, it can be stated that dynamic simulation offers use for many problem areas. Jiang at al. [22] presents the use of this method in the field of production workshop schedule. The authors focused on their framework on the simulation of the production workshop schedule on the genetic algorithm basis. The results, that have been achieved, show that a dynamic model can shorten scheduling times and improve the stability of dynamic planning and has a positive main relevance for production workshop scheduling of manufacturing companies. Dynamic simulation can be used for both production processes and for simulation of mechanical and physical processes. Wang at al. [23] applied dynamic simulation in the research of tire high-speed-rolling condition. They realized their research using the program Abaqus and came to conclusions that give references for optimizing and designing vehicles and roadways. Dynamic simulation is also used in the field of fuels and energy industries, as described by Zheng et al. [24] or Xia et al. [25].

What is also often lacking in articles about simulation is to show the results of applying simulation on a practical case study. The aim of the paper is to present the practical application of the method of dynamic simulation by design of production system on the example of the case study of pressing shop, and it was used the proposed framework for dynamic simulation of production systems.

\section{SIMULATION AND SYSTEMS MODELLING IN THEORY}

Simulation is a technique to imitate the operation of real-world processes and facilities. The processes or facilities are usually called a system, and compromise of entities (e.g. people, machines, things) working together to achieve something, to have some output, as Law stated in [26]. 
In order to be able to simulate the workings of a system, we create its model, which is a representation of both structure and workings of said system, as Anu Maria defined in [27]. The model itself is then a set of assumptions about how the system works, often in the form of logical or mathematical relationships. Through the model, we try to gain an understanding of how the real-life system works.

We basically distinguish between two types of systems: static systems and dynamic systems. Static systems are those, which output response to input does not change in time that means that the output is always the same if the input stays the same. Dynamic systems are those that have a response to the input that is not instantaneously proportional, may show disturbances and even if the input stays constant, they can respond to input signals, disturbance signals and so on. So the output does not have to be the same even if given the exact same input. For further reading, we recommend [28].

Production systems are dynamic and they must take the system development and systems environment into consideration when it comes to their design. The production systems definition, or the most basic model, is that the input is transformed through certain processes into output. The input is resources, which can be classified as materials, information, customers, fixed assets, consumables and human resources. The outputs are then products, services and information. The process itself is a way we transform input to the required output. For further reading, [29] and [30] are recommended.

To be able to simulate, we need to first create a representation of the system described in the previous section - to create its model. Modelling is a process of model creation and is one of the crucial steps of using simulation. Staša in [31] describes a very basic framework for simulation, although we can find a more suitable framework provided by Anu Maria in [27] and which includes the following steps:

1. Identify the problem.

2. Formulate the problem.

3. Collect and process real system data.

4. Formulate and develop a model.

5. Validate the model.

6. Document model for further use.

7. Select an appropriate experimental design.

8. Establish experimental conditions for runs.

9. Perform simulation runs.

10. Interpret and present results.

11. Recommend a further course of action.

\section{PROPOSED FRAMEWORK FOR DYNAMIC SIMULATION OF PRODUCTION SYSTEMS}

We propose dynamic simulation model for building production systems which are based on a basic model by Staša [31] and we can also find similarities (but we will also discuss differences) with the model presented by Anu Maria. The overview of the whole framework is presented in Fig. 1.

\subsection{Problem identification and formulation}

The first step is problem identification - it means we must set goals of production quantity, see what machinery we must use (if there is any - either one that is currently used or one we are obliged to buy) and formulate what we want to achieve with the new production system. We also must keep in mind what other systems interact with the production system and 
include their restrictions to our system - we need to establish the so-called scope of the model.
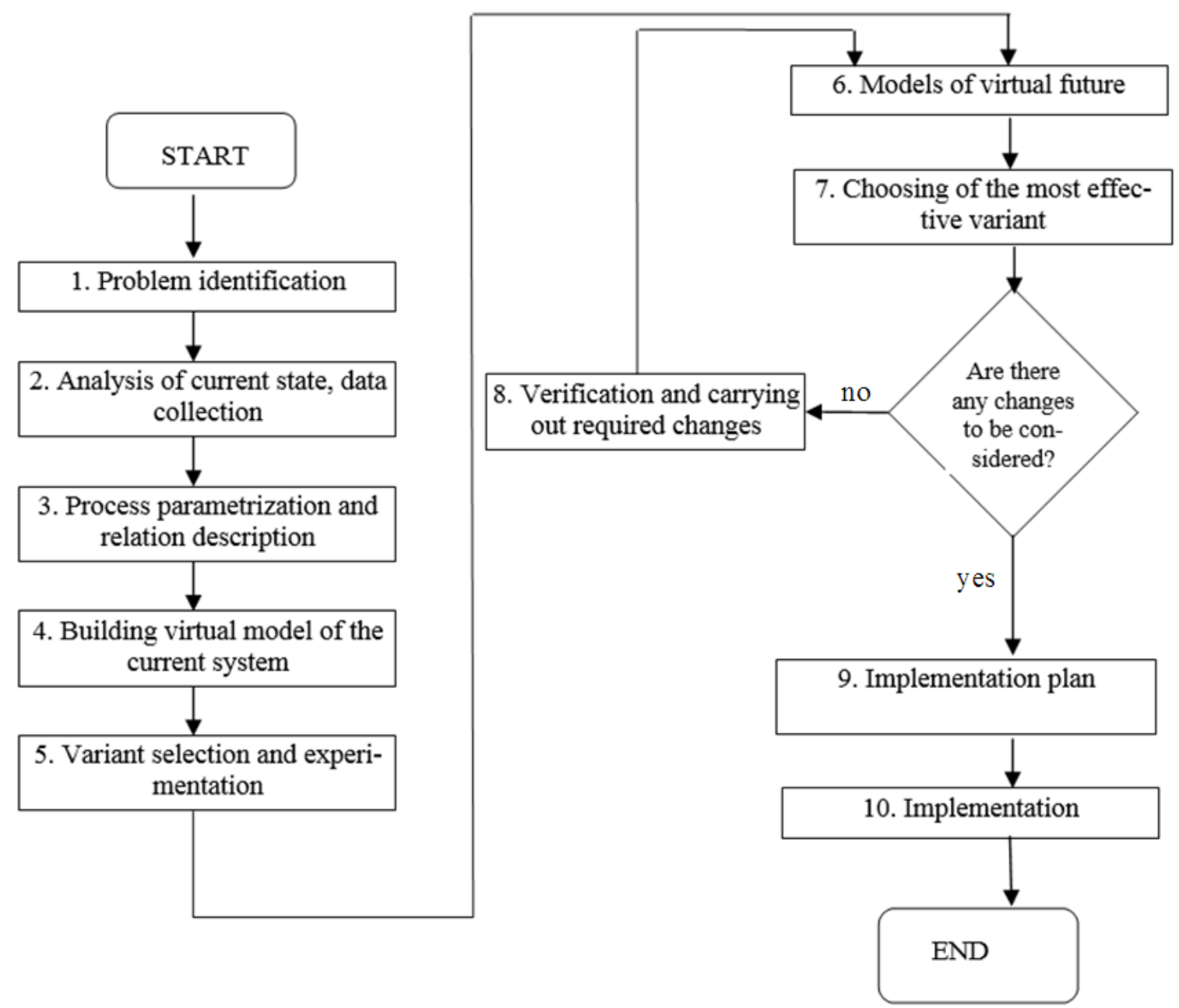

Figure 1: Framework visualization.

\subsection{Current state analysis and data collection}

At this step, we need to analyse the current production system, if there is any - map production flow, logistical flow, find current bottlenecks and try to remove them before simulation. The assumption is that there is always currently existing production system as the simulation is used mainly for larger companies and more complicated problems. If there is not a currently used production system, we can analyse at least collect publicly available data e.g. how long will this kind of transport take, how long used machinery operates and so on.

From practical point of view and from the experience of the authors of this article, it is necessary to closely cooperate not only with the workers who put required data into information system but also with the workers that take any part in the process e.g. example manual workers, line leaders and leaders of the whole shop floor.

\subsection{Process parametrization and relation description}

In this step, it is required to parametrize all the data (how long it takes to produce one piece on which machine, determine size and frequency of work orders, production process breaks and so on), to determine lead times, the time needed for manipulation and so on. We try to obtain real statistical data to use in the model and average them, to make them parameters. We also parametrize the stochastic data. 
This is a difference from Anu Maria model, where she suggests using probability distributions and so on - we try to use real data and use probabilities only when necessary (probability of machine breakdown). And even this we later parametrize for better results: when using the before mentioned example, we average after how many pieces the machine breaks down.

\subsection{Building a virtual model of the current system}

In this step, the model is rebuilt so it could be run on a computer. It is necessary to program all the connections and relationships of the model, which then shows accurate process performance and running. It is also necessary to consult this in a team of consultants, managers, workers and programmers, so it is accurate: it would be very hard to fix the problems later. Good documentation of such a model is also necessary. Very important is to validate the model with the real system by running it with known parameters and inputs from history and compare its results with real historical outputs.

\subsection{Variant selection and experimentation}

We need to prepare variants of the solution - more variants are better, although each variant of solution costs money. But, as Fotr and Hořický state in [32]: the lesser variants we produce, the lower the hope to find an efficient solution.

It is crucial to work in a team here, so we can ensure that we will not produce a variant that is unrealistic in terms of financial costs, space requirements, qualification of workers and so on. It is also necessary to base these variants on data obtained in steps problem identification and current state analysis, so we meet goals set in these steps and mind all possible constraints. Then it is necessary to analyse these variants and experiment with them alter them, discuss different techniques used, discuss possible workings of systems and so on.

\subsection{Models of virtual future}

Given the nature of dynamic simulation and the complexity of models being created, it is necessary to pick 2-3 variants with the most promising results to model. The virtual model of future state needs to be well documented and must include the most important solutions from variant selection - the differences between selected variants should be bigger (not only in some of the parameters but in terms of the whole solution).

\subsection{Choosing the most effective variant}

In this step, we need to choose which variant is going to be used. It is necessary to determine it by pre-defined parameters and results that characterize the process the best. Then we pick the variant with the best results.

\subsection{Verification and carrying out required changes}

This step is intertwined with steps models of virtual future and choosing the most effective variant. It means we try to find new solutions to some of the problems, remove some bottlenecks in the selected model (or models), we change the concept of the solution or we change some of the parameters. This step can be repeated multiple times and we need to process steps models of virtual future and choosing the most effective variant every time we make some change.

This is where the dynamic simulation is most helpful because we can quickly adapt to some minor problems, parameter changes and so on [33]. We can then come up with solutions to minor problems, which affect the productivity of variants to a great extent. 


\subsection{Implementation plan}

Implementation plan can be visualized in the new system and the model can also be used to plan gradual implementation of the new production system over the course of weeks and months; so we do not affect production that much. It can tell us where to begin, what can be done with production running and when it is more beneficial to stop production altogether.

\subsection{Implementation of the new system}

The practical implementation can be carried out even without the personnel running the simulation. It can be also beneficial to include the whole team because we can find something that we are not able to implement in the real system and can simulate and find the best solution quickly. It is also desirable to have test run of the system to check if everything is running according to the simulation and if not it might be good to update the model (which becomes model of system in the current state) and try to simulate everything to continue in improvements according to PDCA policy or just document how well the simulation captured the workings of production system.

\section{FRAMEWORK APPLICATION ON PRESSING SHOP PRODUCTION SYSTEM}

The goal of simulation in this project was to ensure that pressing shop will be able to produce 75.000 pcs of engines, which served as $100 \%$ ratio, after required modernization. It was estimated, that the pressing shop will produce $113 \%$ and $140 \%$ after several years. The goal of the simulation was to ensure that the pressing shop will be capable to produce such quantity, to check the required frequency of operational personnel actions and required capacities of crucial pressing shop nodes, to determine the required count of material handling equipment and required personnel to operate it and verification of shelf based warehouse system.

The first step - problem identification - was carried out by an internal team. They were asked to come up with a solution that would integrate new production machinery into the process. They came up with the before mentioned goals and problem definitions. Due to very complicated material and logistical flows, they contacted consultants who had access to simulation software.

The analysis was carried out in a team, which mixed both internal and external personnel. The teams mapped the production flow and tried to identify the bottlenecks and reserves of the production system.

As it was stated in section 3, it is necessary to work not only with personnel who report data to the information system but also with the workers who make any kind of input into the process. The data in the information systems can be biased due to different circumstances. For example, the different skill level of the personnel is not considered (as it happened in this project) and the team also found out that some of the standardized times were off, which was determined only after the team used chronometric tables and careful time study.

It is also important to mention that the company benefited even from this step: the norm times were actualized, the data for further process analysis were collected and the documentation of processes was created. The most important data collected from the ERP system were checked against real-time evidence.

During the realization of the third step, we reconfirmed that the selected framework of the project was used correctly: we found out there were imperfections in logistical flows. Detailed examination of the personnel actions at every node and the process of material supply to every workplace was conducted not only on material needed for immediate production but for 
all components needed (e.g. buckles, belts and arbours) - thanks to that, the team has found processes that needed improvement and brought results before the project realization itself.

The optimization of material flows was needed mainly not in the question of products or materials for them, but for other needed components as this problem was overlooked by the company workers. The analysis brought better clarification and prioritization in handling required materials. These changes were implemented before creating the model.

The virtual model of the production system in a pressing shop was made in WITNESS software in accordance with the plans and data from all the production processes. The model was designed with regard to the possibility to ensure the capability of producing for all the capacity variants. Simulation time was set to one year and during this time, all production processes were observed. Statistics were then calculated for one month because production batches were also repeating each month with the exception of the casting process, in which they were repeating each week.

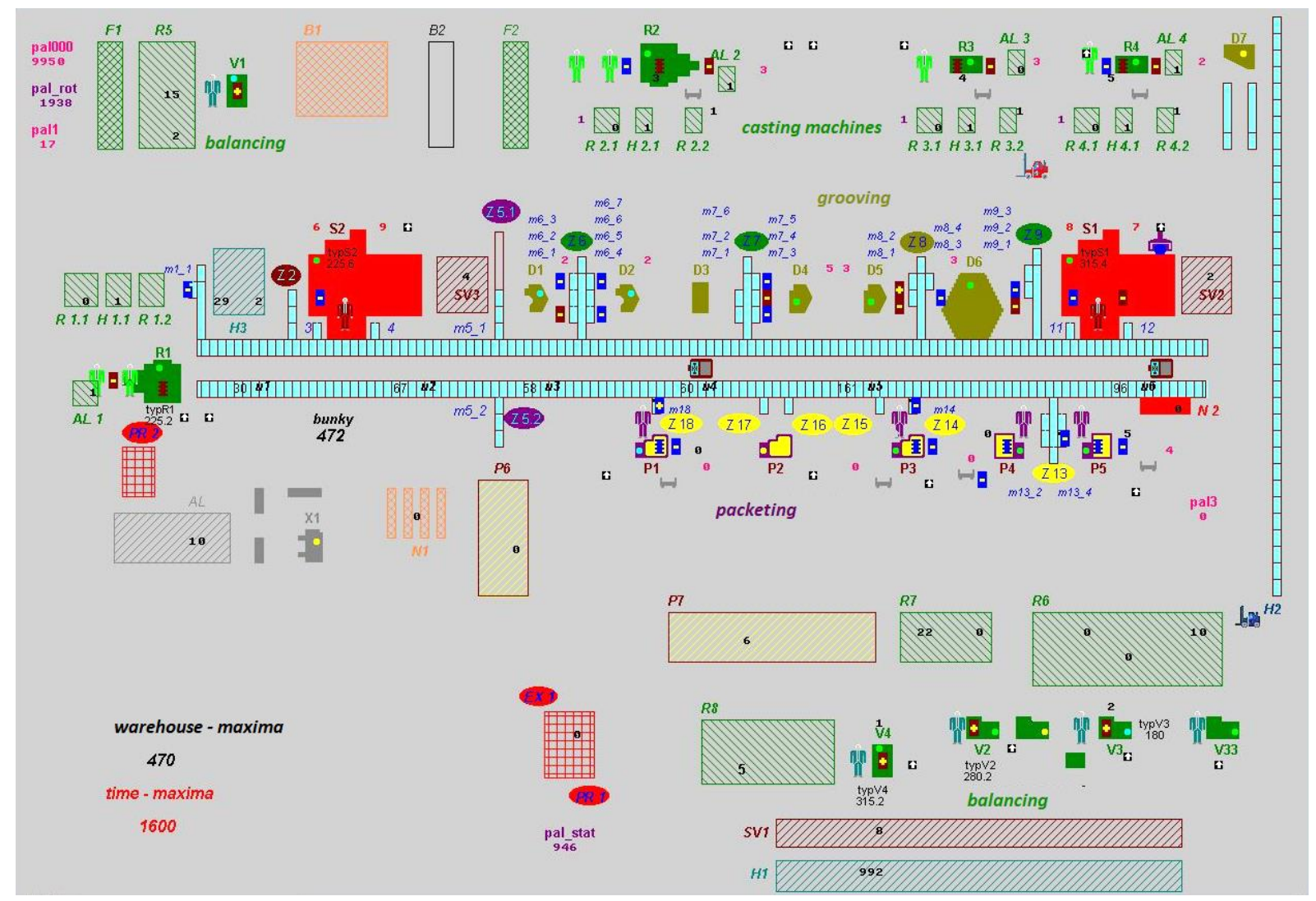

Figure 2: Virtual model built in WITNESS simulation software.

The input files were designed in a way that it is easy to change them, which is important when for example we change the number of iron slates on pallets or input batches for machines.

The model also includes setting up input batches based on required production of a pressing shop and their parameters include failure rate, setup times and required operation personnel actions.

As a scope of the system had to be set as very comprehensive, we also included the operation of forklifts, which bring the required material, transport empty and full pallets to the warehouses (Fig. 3), transport required components to all production nodes and handle the loading of goods in the expedition. In the model, we also included crane, which handles both Schuller presses.

The model was also built in a way that we could look at the following parameters: 
- number of goods produced in 1 year (respectively one month),

- usage of machinery including their downtimes,

- usage of forklifts for pallet handling,

- usage of the shelf-based warehouse system,

- usage of the crane handling Schuler presses,

- rolling rate of fill-up of a shelf and time of using it on a maximum capacity,

- continuity of production.

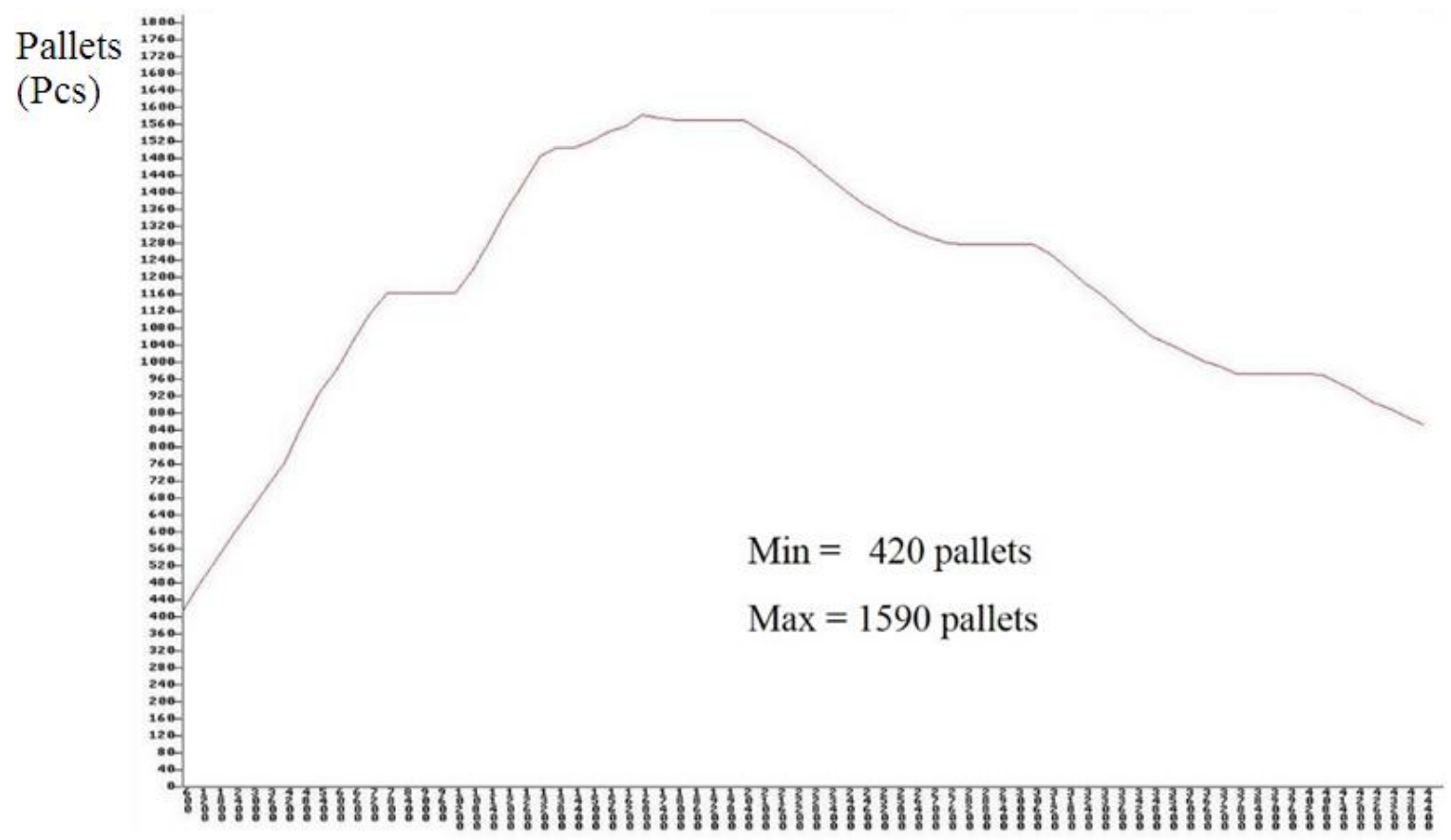

Simulation time (s)

Figure 3: The curve of the full (total) repletion of the rack.

When all these parameters were set, the team checked historical output against historical parameters, which proved that the model was made according to the real output of the pressing shop.

In this step, thanks to dynamic simulation, the maximum capacity of the current production system was established, which was important for an implementation plan of the new solutions. In addition, some proposals on how to remove some of the bottlenecks were made. The bottlenecks were identified by means of continuous and final results of simulation experiments, where the use of individual workplaces, positions and processes was monitored, also the ability of workplaces to produce the planned and required number of semi-finished goods and final products.

The next step was to select different variants and experiment with them. The simulation was carried out in all three variants (producing 75.000 motors a year, with an increase to $113 \%$ and $140 \%$ ). Thanks to the simulation, new bottlenecks were found, which appeared when new machinery was added into the virtual model. During the experimental phase, these bottlenecks were removed.

In this step, we also had to, according to with the proposed framework, apply some changes to the input data, so we would be able to simulate production of required quantities with keeping the input batches on the same level (in accordance to number of operational steps, after which we need to replace or repair machinery).

In the step Models of the virtual future, the models of three variants were fine-tuned so the simulation outputs could be properly presented. This included more work in the Witness 
simulation software and a deeper understanding of the proposed variants. It was necessary to include stochastics data, which became more important in changed processes (average sick time of the personnel, downtime of forklifts and so on).

New bottlenecks were found, which were not present in the present state and appeared after adding new machinery to the model - which is common both in theory and in practical application. Most of the new bottlenecks were linked with the insufficient output of older machinery. Some rebuilds and one purchase of the new machine were purposed.

In the seventh step, the simulation outputs of all variants were presented to the team. It was observed that after carrying out necessary removal of bottlenecks, which were found thanks to the simulation, the pressing shop can increase production to required levels with partial reserves.

\section{RESULT}

During the analysis of the simulated process, it was mapped in detail, product and material flow were defined, material flows, including the operation of nodes, were clarified. Based on the results of simulation experiments and analysis, measures were subsequently proposed concerning changes in the number of employees at individual workplaces. The measures were implemented with regard to ensuring the functioning of the relevant workplace and workload of workers. All the above-mentioned measures were implemented with respect to already realized analyses and identification of bottlenecks in the production process.

Thanks to the simulation, the following process changes were also identified: the Schuler presses can work only on a two-shift basis. If the workers will be trained and contracted to be universal, the third specialized shift can be cancelled. The pressing shop will not have to use two employees which means that the expenses will be lowered by 28.000 EUR.

During the course of the project, some partial changes were made. That included changes of parameters of some machinery and new implementation of storing semi-finished products in the shelf-based warehouse (Fig. 4). All changes were integrated into simulation models and the simulation was carried again, so it would be possible to come up with finalized models.

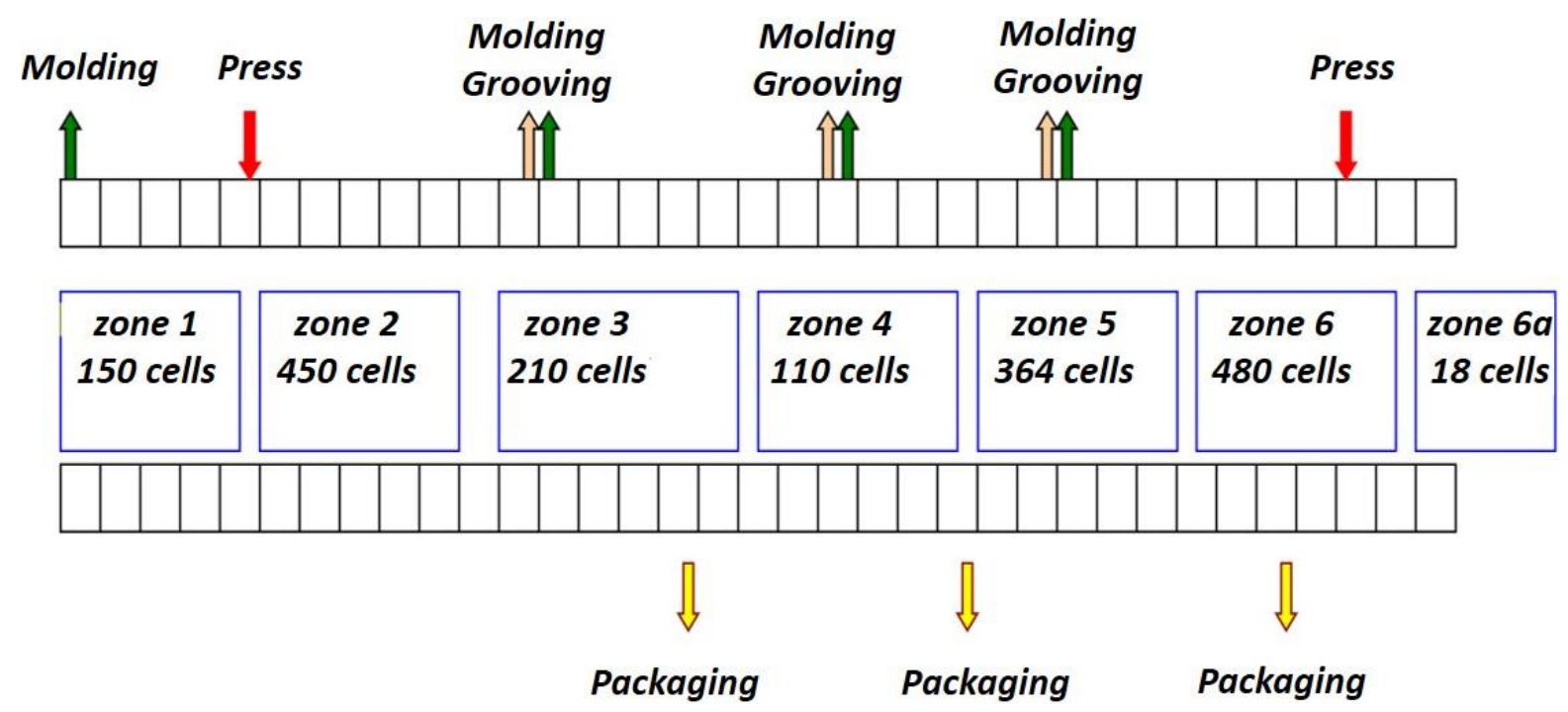

Figure 4: Allocation of racks according to technological flows of materials.

Related to the new shelf-based warehouse were two positive process changes: The workers at presses could also handle the balancing device without lowering their output, thanks to the new warehouse - which brought another 28.000 EUR savings in expenses. 
Another important change was work reorganization at casting machines: the workers could take sheets of metal from the conveyor belt themselves, which lead to fork-lift optimization - the whole pressing shop needs only two fork-lifters after the change, which means savings of 28.000 EUR. It was also determined by simulation that the second forklift is not needed during the third shift when there is no dispatch of finished goods. That brought savings of about 12.000 EUR.

In the ninth step, the implementation plan was produced, which comprised of the installation of the new equipment, carrying out required changes on other workplaces and synchronization of the new system. The implementation was longer than expected but included changes in work agreements - as the team proposed more universal workers - and incorporating new machinery without a too severe impact on the output of the pressing shop during the implementation itself.

The system was implemented according to the selected simulation variant model and checked again. All the suggested changes were carried out and the project was successful the real output of the pressing shop has not attained maximum capacity, but the model proved to be very close to the real output in real conditions.

The project itself was successful because we could find a way, how to include new machinery and change the production system for the pressing shop. After applying the changes suggested by dynamic simulation, the pressing shop can build 105.000 motors a year with enough reserves for unexpected production.

The project was long-term (the realization was planned over the course of two years) and during its course, the dynamic simulation proved very beneficial, because thanks to using dynamic model, it was possible to react to changes of range of products (different lead times) and changes in used machinery.

Thanks to selecting a larger scope of the project, we were able to determine how changing production system affects warehousing, which resulted in a more accurate simulation of the whole company.

\section{CONCLUSION}

This paper presents a working framework for using dynamic simulation together with a case study of its' practical implementation. It discusses some differences in the framework form the basic framework and specifies required steps with examples and further instructions for successfully using dynamic simulation in the specific case of production system design.

The paper presents the active use of dynamic simulation as a powerful analytical tool in the field of production logistics. The paper defines and elaborates requirements for input information, which are necessary for the realization of dynamic simulation within the logistics. At the same time, the paper presents possibilities that provide the obtained information in term of their application to the real enterprise environment. The paper presents an overview of the application possibilities of dynamic simulation in the field of production logistics and at the same time, the paper presents general instruction how to use dynamic simulation and process the obtained information from simulation experiments. At the same time, the presented example points out the possibilities of using dynamic simulation to increase production efficiency.

Further research would help determine how the dynamic simulation can be beneficial after designing the whole system and putting it in use. However, this framework is the first step to successfully use dynamic simulation techniques.

The paper provides verification that the dynamic simulation can be used to solve real problems in industrial practice. It points out a possible procedure for solving tasks related to increasing efficiency, identification of bottlenecks. The paper also verifies the framework for 
a dynamic solution, which is applicable for solving a wide range of similar tasks related to the design of production workplaces. The paper can serve as a guide for solving tasks for workers at the department of logistics, who are reserved to use computer simulation tools. For researchers, the paper provides a starting point for exploring the dynamics of production systems, while actively taking into account internal interactions within a complex logistics and production systems. At the same time, the presented approach and the created model have a perspective in the field of training for the solution of the model situation, preparation of training and training of new employees.

\section{ACKNOWLEDGEMENT}

This work is a part of these projects: VEGA 1/0600/20, KEGA 012TUKE-4/2019, APVV SK-SRB18-0053.

\section{REFERENCES}

[1] Cschornack, P.; Kliemann, J. (1976). Interference analysis for automatic equipment in chemicalindustry and conclusions for designing production system in the automated plant, Chemische Technik, Vol. 28, No. 9, 573-574

[2] Inman, R. R.; Blumenfeld, D. E.; Huang, N.; Li, J. (2003). Designing production systems for quality: research opportunities from an automotive industry perspective, International Journal of Production Research, Vol. 41, No. 9, 1953-1971, doi:10.1080/0020754031000077293

[3] Fragapane, G. I.; Zhang, C.; Sgarbossa, F.; Strandhagen, J. O. (2019). An agent-based simulation approach to model hospital logistics, International Journal of Simulation Modelling, Vol. 18, No. 4, 654-665, doi:10.2507/IJSIMM18(4)497

[4] Semjon, J. (2013). The procedure designing production systems based on CA methods, Applied Mechnaics and Materials, Vol. 282, 246-251, doi:10.4028/www.scientific.net/AMM.282.246

[5] Zajickova, J.; Nedoma, P. (1978). Application of language GPSS for purposes of designing production systems, Ekonomicko-Matematicky Obzor, Vol. 14, No. 2, 128-141

[6] Kostanjsek, G.; Gajsek, B. (2017). The impact of workplace supply on productivity in functionally organized layouts, Tehnicki glasnik - Technical Journal, Vol. 11, No. 1-2, 35-44

[7] Hajduk, M.; Sukop, M.; Semjon, J.; Janos, R.; Varga, J.; Vagas, M. (2018). Principles of formation of flexible manufacturing systems, Tehnicki vjesnik - Technical Gazette, Vol. 25, No. 3, 649-654, doi:10.17559/TV-20161012132937

[8] Terkaj, W.; Tolio, T.; Valente, A. (2009). Focused flexibility in production systems, ElMaraghy, H. (Ed.), Changeable and Reconfigurable Manufacturing Systems, Springer, London, 47-66, doi:10.1007/978-1-84882-067-8 3

[9] Semini, M.; Fauske, H.; Strandhagen, J. O. (2008). Which manufacturing logistics decisions are supported by operational research? A literature survey, Koch, T. (Ed.), Lean Business Systems and Beyond, Springer, Boston, 231-238, doi:10.1007/978-0-387-77249-3 24

[10] Tabuchi, S.; Osaki, H.; Kajihara, Y.; Munesawa, Y. (2001). A method for design production system with multi energy resources, Memoirs of the Faculty of Engineering, Okayama University, Vol. 35, No. 1-2, 183-189

[11] Chatterjee, P.; Athawale, V. M.; Chakraborty, S. (2010). Selection of industrial robots using compromise ranking and outranking methods, Robotics and Computer-Integrated Manufacturing, Vol. 26, No. 5, 483-489, doi:10.1016/j.rcim.2010.03.007

[12] Sass, L.; Botha, M. (2006). The instant house: a model of design production with digital fabrication, International Journal of Architectural Computing, Vol. 4, No. 4, 109-123, doi:10.1260/147807706779399015

[13] Hsieh, S.-J. (2002). Hybrid analytic and simulation models for assembly line design and production planning, Simulation Modelling Practice and Theory, Vol. 10, No. 1-2, 87-108, doi: $\underline{10.1016 / \mathrm{S} 1569-190 \mathrm{X}(02) 00063-1}$ 
[14] Yang, T.; Kuo, Y.; Su, C.-T.; Hou, C.-L. (2015). Lean production system design for fishing net manufacturing using lean principles and simulation optimization, Journal of Manufacturing Systems, Vol. 34, 66-73, doi:10.1016/j.jmsy.2014.11.010

[15] Dias, L. M. S.; Pereira, G. A. B.; Vik, P.; Oliveira, J. A. (2018). Layout and process optimisation: using computer-aided design (CAD) and simulation through an integrated systems design tool, International Journal of Simulation and Process Modelling, Vol. 9, No. 1-2, 46-62, doi:10.1504/IJSPM.2014.061437

[16] Vik, P.; Dias, L.; Pereira, G.; Oliveira, J.; Abreu, R. (2010). Using Simio for the specification of an integrated automated weighing solution in a cement plant, Proceedings of the 2010 Winter Simulation Conference, 1534-1546, doi:10.1109/WSC.2010.5678915

[17] Vik, P.; Dias, L.; Guilherme, P.; Oliveira, J. (2010). Improving production and internal logistics systems - an integrated approach using CAD and simulation, Proceedings of the $3^{\text {rd }}$ International Conference on Information Systems, Logistics and Supply Chain - Creating Value Through Green Supply Chains, 14-16

[18] Popovics, G.; Pfeiffer, A.; Monostori, L. (2018). Generic data structure and validation methodology for simulation of manufacturing systems, International Journal of Computer Integrated Manufacturing, Vol. 29, No. 12, 1272-1286, doi:10.1080/0951192X.2016.1187296

[19] Sargent, R. G. (1999). Validation and verification of simulation models, Proceedings of the 2004 Winter Simulation Conference, 39-48, doi:10.1109/WSC.1999.823050

[20] Xu, W.; Yin, Y. (2018). Functional objectives decision-making of discrete manufacturing system based on integrated ant colony optimization and particle swarm optimization approach, Advances in Production Engineering \& Management, Vol. 13, No. 4, 389-404, doi:10.14743/ apem2018.4.298

[21] Sadeghpour, H.; Tavakoli, A.; Kazemi, M.; Pooya, A. (2019). A novel approximate dynamic programming approach for constrained equipment replacement problems: a case study, Advances in Production Engineering \& Management, Vol. 14, No. 3, 355-366, doi:10.14743/ apem2019.3.333

[22] Jiang, P.; Ding, J. L.; Guo, Y. (2018). Application and dynamic simulation of improved genetic algorithm in production workshop scheduling, International Journal of Simulation Modelling, Vol. 17, No. 1, 159-169, doi:10.2507/IJSIMM17(1)CO3

[23] Wang, Y.; Lu, Y. J.; Si, C. D.; Sung, P. (2016). Tire-pavement coupling dynamic simulation under tire high-speed-rolling condition, International Journal of Simulation Modelling, Vol. 15, No. 2, 236-248, doi:10.2507/IJSIMM15(2)4.332

[24] Zheng, M.; Li, X.; Wang, M.; Guo, L. (2019). Dynamic profiles of tar products during Naomaohu coal pyrolysis revealed by large-scale reactive molecular dynamic simulation, Fuel, Vol. 253, 910-920, doi:10.1016/j.fuel.2019.05.085

[25] Xia, G.; Lv, Y.; Cheng, L.; Ma, D.; Jia, Y. (2019). Experimental study and dynamic simulation of the continuous two-phase instable boiling in multiple parallel microchannels, International Journal of Heat and Mass Transfer, Vol. 138, 961-984, doi:10.1016/ j.ijheatmasstransfer.2019.04.124

[26] Law, A. M. (2015). Simulation Modeling and Analysis, $5^{\text {th }}$ edition, McGraw-Hill, New York

[27] Maria, A. (1997). Introduction to modelling and simulation, Proceedings of the $29^{\text {th }}$ Winter Simulation Conference, 7-13

[28] Woods, R. L.; Lawrence, K. L. (1997). Modeling and Simulation of Dynamic Systems, $1^{\text {st }}$ edition, Prentice-Hall International, London

[29] Fiala, P. (2013). Modely Produkčnich Systemu, $2^{\text {nd }}$ edition, Oeconomica, Prague (in Czech)

[30] Dlouhy, M.; Fabry, J.; Hladik, T.; Kuncova, M. (2007). Simulace Podnikovych Procesu, $1^{\text {st }}$ edition, Computer Press, Brno (in Czech)

[31] Stasa, P. (2014). Modelling and Simulation (in Czech), VŠB-TU Ostrava, Ostrava

[32] Fotr, J.; Horicky, K. (1988). Rozhodování, Řešeni rozhodovacich problémů v řizení (Deciding, Solutions of Decision Problems in Management), $1^{\text {st }}$ edition, Institut ř́zení, Prague (in Czech)

[33] Bhat, B. N. S. (2008). Usability factors to be considered in a simulation tool while designing production system, International Journal of Interactive Design and Manufacturing, Vol. 2, No. 4, 225-232, doi: $\underline{10.1007 / \mathrm{s} 12008-008-0052-6}$ 